\title{
Konflik Budaya Lokal Pada Masyarakat di Pulau Flores \\ (Sebuah Analisis Komunikasi Lintas Budaya)
}

\author{
Jonas Klemens Gregorius Dori Gobang \\ Program Studi Ilmu Komunikasi Universitas Nusa Nipa Maumere, Flores, NTT.
}

\begin{abstract}
Cultural conflict can occur anywhere, let alone in a place where there are fundamental differences about the culture and society supporting a culture. Local cultural conflicts in society can be triggered by various factors both in ideological and practical level. This cultural conflict can be transformed into something that benefits society supporting different cultures when it can be properly managed through the appropriate approach. This study tries to present some aspects of cross-cultural communication theory approach in scrutinizing the conflict and manage cross-cultural conflict can be a potential conflict in order to establish brotherhood and unity in the diversity of cultures that exist on the island of Flores. This study can be used as a reference to see various forms of cultural conflict found in other cultures in various places.
\end{abstract}

Key Words : Conflict, culture, society.

\begin{abstract}
Abstrak
Konflik budaya dapat terjadi di mana saja, apalagi di tempat di mana terdapat perbedaanperbedaan fundamental tentang budaya dan masyarakat pendukung suatu kebudayaan. Konflik budaya lokal pada masyarakat dapat dipicu oleh berbagai macam faktor baik yang bersifat ideologis maupun dalam tataran praksis. Konflik budaya ini dapat diubah menjadi sesuatu yang menguntungkan masyarakat pendukung kebudayaan-kebudayaan yang berbeda bila dapat dikelola secara baik dan benar melalui pendekatan yang tepat. Penelitian ini mencoba menghadirkan beberapa aspek dari pendekatan teori komunikasi lintas budaya dalam mencermati konflik dan mengelola konflik lintas budaya agar konflik dapat menjadi potensi untuk membangun persaudaraan dan persatuan di dalam keragaman budayabudaya yang ada di Pulau Flores. Penelitian ini dapat dijadikan acuan untuk melihat berbagai bentuk konflik budaya yang terdapat pada kebudayaan lain di berbagai tempat.
\end{abstract}

Kata Kunci : Konflik, budaya, masyarakat.

\section{Pendahuluan}

Flores adalah bagian dari provinsi Nusa Tenggara Timur. Pulau ini dibagi menjadi delapan kabupaten; dari barat ke timur sebagai berikut : Manggarai Barat dengan ibukota Labuan Bajo, Manggarai dengan ibukota Ruteng, Manggarai Timur dengan ibukota Borong, Ngada dengan ibukota Bajawa, Nagekeo dengan ibukota Mbay, Ende dengan ibukota Ende, Sikka dengan ibukota Maumere, dan Flores Timur dengan ibukota Larantuka. Flores, dari bahasa Portugis yang berarti "bunga" termasuk dalam gugusan Kepulauan 
Sunda Kecil bersama Bali dan NTB, dengan luas wilayah sekitar $14.300 \mathrm{~km}^{2}$. Penduduk di Flores, di tahun 2007, mencapai 1,6 juta jiwa.

Dilihat dari kondisi geografis, keragaman suku, budaya, bahasa, agama dan historis dari Pulau Flores, maka dapat ditemukan berbagai bentuk konflik budaya antar masya-rakat penganut kebudayaan yang berbeda yang menghuni potongan kecil pulau yang bernama Flores itu. Konflik budaya antar masyarakat di Pulau Flores sering terjadi mulai dari masalah yang sederhana hingga masalah yang kompleks.

Konflik budaya yang sederhana antar masyarakat di Pulau Flores dapat dipicu oleh kesalahan dalam berkomunikasi. Kesalahan komunikasi dapat menimbulkan konflik antar penganut budaya yang berbeda. Kesalahan komunikasi dapat terjadi secara verbal maupun non-verbal. Kesalahan komunikasi ini pun dapat mempengaruhi lapisan budaya, sosio-budaya dan psikobudaya. Dari konflik budaya yang sederhana tersebut dapat juga menimbulkan terjadinya konflik budaya yang kompleks. Hal ini terjadi karena setiap orang yang terlibat dalam komunikasi antarbudaya memiliki sifat etnosentris dan primordial.

Komunikasi antarbudaya dalam suatu masyarakat sangat penting agar tidak terjadinya salah penyampaian informasi antar anggota dalam suatu masyarakat. Tujuan dari komunikasi antarbudaya adalah untuk mensinkronkan dan menyatukan seluruh aspek untuk kepentingan bersama dalam mencapai tujuan dari masya-rakat di dalam satu kawasan pulau. Namun dalam berinteraksi terjadi kesalahan komunikasi yang dapat menyebabkan terjadinya salah pengertian (misunderstanding). Kesalahan komunikasi inilah yang pada gilirannya menimbulkan konflik budaya pada masyarakat di Pulau Flores.

Tulisan ini ingin membongkar terjadinya konflik budaya pada masyarakat di Pulau Flores. Kesalahan komunikasi melalui permainan bahasa kerap terjadi pada masyarakat di Pulau Flores dengan budaya yang berbeda yang menimbulkan konflik budaya, dapat kita temukan dalam pemba-hasan lebih lanjut dari tulisan ini.

\section{Landasan Teori}

William B. Gudykunst (2001: 2550) menawarakan beberapa pendekatan dalam menempatkan budaya pada lintasan teori-teori komunikasi. Sekurangkurangnya lima pendekatan yang dinyatakan oleh kedua penulis tersebut dalam karya mereka.

Pertama, budaya atau kebudayaan itu dapat menjadi sudut pandang dalam proses komunikasi di dalam teori-teori. Gudykunst dan Lee menyebutkan contoh untuk men-jelaskan pendekatan yang pertama, yaitu: sudut pandang budaya sebagai bagian dari teori konstruktivis, yang ditulis oleh Applegate dan Syper, tahun 1983 dan 1988. Selain itu contoh yang lainnya adalah : sudut pandang budaya sebagai bagian dari teori koordinasi manajemen dan makna seperti yang diulas oleh Cronen, Chen, dan Pearce pada tahun 1988.

Kedua, komunikasi dapat men-jadi sudut pandang untuk kreasi atau cipta budaya. Hal ini lebih lanjut dijelaskan dengan gamblang pada bab 3 buku mereka, khususnya pada diskusi tentang komunikasi budaya yang ditulis oleh Philipsen.

Ketiga, teori-teori didesain pada satu budaya dan dapat digeneralisasikan pada budaya-budaya lainnya, atau budaya dapat diterapkan sebagai batasan kondisi 
dari proposisi yang dibangun oleh teoriteori.

Keempat, teori-teori dapat dipakai untuk menjelaskan komu-nikasi antara masyarakat dari kebudayaan yang berbeda.

Sedangkan yang kelima, Gudykunst dan Lee menjelaskan bahwa teori-teori dapat didesain untuk menjelaskan bagaimana komunikasi merubah lintasan budaya-budaya.

Gudykunst dan Lee mengawali penjelasan dengan mengetengahkan bagaimana budaya atau kebudayaan itu dapat digunakan secara teoretis untuk mengkonstruksi teori-teori komunikasi. Nah, dapat kita katakan bahwa budaya memberikan kontribusi bagi upaya menemukan teori komunikasi di satu sisi. Dan di sisi lain, teori-teori komunikasi dapat memberikan perspektif dalam relasi atau pun dialog antar budaya atau yang disebut oleh penulis sebagai "dialog kehidupan”.

Selain itu, untuk dapat mengonfirmasi temuan dalam penelitian ini, peneliti juga menggunakan gagasan tentang permainan bahasa dalam komunikasi antarbudaya pada masyarakat di Pulau Flores. Bahasa mencerminkan budaya. Makin besar perbedaan budaya, makin perbedaan komunikasi baik dalam bahasa maupun dalam isyarat-isyarat nonverbal. Makin besar perbedaan antara budaya (dan, karenanya, makin besar perbedaan komunikasi), makin sulit komunikasi dilakukan. Kesulitan ini dapat mengakibatkan, misalnya, lebih banyak kesalahan komunikasi, lebih banyak kesalahan kalimat, lebih besar kemungkinan salah paham, makin banyak salah persepsi, dan makin banyak potong kompas (bypassing) (Tubbs dan Moss, 1996: 236-238).
"Permainan" bahasa yang dimaksudkan dalam tulisan ini mengarah kepada penggunaan bahasa verbal dan non-verbal yang dilatarbelakangi oleh budaya dari pengguna bahasa itu sendiri. Permainan bahasa oleh anggota dari suatu suku di Pulau Flores tentu saja dipengaruhi oleh kosakata dan gestikulasi dari suku tersebut. Sedangkan permainan bahasa dari suku yang lain yang juga mendiami Pulau Flores dipengaruhi oleh kosakata dan gestikulasi budaya suku tersebut.

Hofstede (dalam Mulyana, 2012) menegaskan bahwa budaya adalah pemograman kolektif atas pikiran yang membedakan anggota-anggota suatu kategori orang dari kategori lainnya.

Sehubungan dengan terjadinya interaksi antara orang-orang yang berasal dari budaya yang berbeda dan menetap di satu wilayah atau pulau yang sama, yakni Pulau Flores, maka unsur-unsur budaya yang dapat berpengaruh satu terhadap yang lain adalah : pandangan dan tujuan hidup, konsep diri, norma dan aturan, bahasa (verbal dan nonverbal), konsep waktu, sejarah, mitologi, seni, lembaga sosial, dan artefak.

Perbedaan-perbedaan yang terdapat di dalam masyarakat penganut budaya tertentu di Pulau Flores dapat memicu terjadinya kesalahan komunikasi. Namun semua unsur budaya memiliki fungsinya khususnya bagi masyarakat yang menganut budaya tertentu. Fungsi budaya agar manusia dapat beradaptasi dengan lingkungannya. Salah satu karakter dari budaya dapat dilihat dari fungsi budaya itu sendiri (Martin dan Nakayama, 2004: 74). Sedangkan inti dari budaya adalah komunikasi. Budaya adalah komunikasi dan komunikasi adalah budaya (Edward T. Hall dalam Mulyana, 2012). 


\section{Objek dan Metode Penelitian}

Objek penelitian menjelaskan tentang apa dan atau siapa yang menjadi objek penelitian. Juga dimana dan kapan penelitian dilakukan, dapat juga ditambahkan dengan hal-hal lain jika dianggap perlu. Objek penelitian ini adalah masyarakat anggota dari sukusuku yang terdapat di Pulau Flores dengan ragam tutur atau bahasa yang digunakan dalam berinteraksi antarmasyarakat yang berbeda budaya dan mendiami suatu kawasan atau wilayah tertentu di dalam satu pulau, yaitu Pulau Flores. Penelitian ini dilakukan di Pulau Flores pada komunitas-komunitas yang memiliki perbedaan suku yang mendiami suatu kawasan atau wilayah di Pulau Flores. Selain itu, penelitian ini juga mengamati tentang cara masyarakat di Pulau Flores berkomunikasi baik secara verbal maupun nonverbal.

Metode yang digunakan di dalam penelitian ini adalah metode deskriptif kualitatif. Tujuan dari penelitian ini adalah mengungkap fakta, keadaan, fenomena, dan keadaan yang terjadi saat penelitian berjalan dan menyuguhkan apa adanya. Penelitian deskriptif kualitatif menafsirkan dan menuturkan data yang bersangkutan dengan situasi yang sedang terjadi, sikap serta pandangan yang terjadi di dalam masyarakat, pertentangan 2 keadaan atau lebih, perbedaan antar fakta, pengaruh terhadap suatu kondisi, dan lain-lain. Kegiatan penelitian ini meliputi pengumpulan data, menganalisis data, meginterprestasi data, dan diakhiri dengan sebuah simpulan yang mengacu pada penganalisisan data tersebut.

\section{Hasil Penelitian}

Suku bangsa Flores adalah merupakan percampuran etnis antara Melayu, Melanesia, dan Portugis. Dikarenakan lokasi yang berdekatan dengan Timor, yang pernah menjadi Koloni Portugis, maka interaksi dengan kebudayaan Portugis pernah terjadi dalam kebudayaan Flores, baik melalui genetik, agama, dan budaya.

Sama dengan kekhasan wilayah Nusantara (Indonesia), Pulau Flores* sebagai bagian dari Indonesia juga memiliki keunikannya yaitu keanekaragaman suku, budaya, bahasa dan agama. Karena itu pula dari segi keanekaragaman etnis dan profil manusia serta bahasa, Mendez Correa dalam Nordholf (1971) menyebut Pulau Timor dan sekitarnya (termasuk Flores tentu saja) sebagai daerah melting point atau tempat peleburan berbagai suku bangsa (dalam Kleden, 2007: 305-306).

Rasanya Mendez Correa tidak berlebihan untuk mengatakan seperti tersebut di atas. Hal ini beralasan karena dari studi antropologi ditemukan bahwa profil orang Flores, mengikuti tipologi Protomelayu, Melayu dan Negroid. Ada pula unsur perpaduan antara Europoid, Indome-lanoid dan unsur Australoid dalam hubungannya dengan orang-orang Melanesia dan Papua. Dari segi bahasa, di Flores ada beranekaragam bahasa, yaitu : Bahasa Kedang, Lamaholot, Sikka, Lio, Ende dan Manggarai.

Tentu saja keanekaragaman budaya orang Flores yang digambar-kan ini memiliki berbagai konsekuensi. Salah satu konsekuensinya adalah konflik antarbudaya dari masyarakat yang mendiami wilayah Flores.

\footnotetext{
Nama Flores sesungguhnya diberikan oleh Bangsa Portugis ketika datang ke wilayah kepulauan itu untuk penyebaran agama (gospel) dan mencari "emas" (gold). Flores artinya "Pulau Bunga". Nama asli Pulau Flores sesungguhnya adalah Nusa Nipa yang artinya Pulau Ular atau Pulau Naga. Konon bentuk Pulau Flores seperti naga yang kepalanya berada di Timur dan ekornya di Barat.
} 
Pulau Flores bertetangga dengan beberapa pulau kecil yang termasuk dalam wilayah Propinsi Nusa Tenggara Timur. Pulau-pulau kecil yang mengitari Pulau Flores adalah Pulau Lembata, Adonara, Solor, Komodo, Rinca, dll yang memiliki karakter budaya yang berbeda dari setiap budaya di wilayah kepulauan tersebut.

Kondisi tersebut di atas mempengaruhi corak budaya yang dihidupi oleh masyarakat yang mendiami wilayah tertentu di Pulau Flores. Corak budaya yang berbeda ini juga dipengaruhi oleh faktor lingkungan fisik (alam) selain faktor non-fisik yang mempengaruhi pola tingkah laku orang Flores.

\section{a. Konflik Bahasa dan Simbol Budaya}

Konsep yang dominan terdapat pada budaya orang Flores adalah konsep kolektivisme (collectivism). Hal ini dipicu oleh faktor alam yang secara geografis berbukit-bukit, dengan wilayah padang savana yang tidak terlalu luas untuk usaha ternak tradisional selain mata pencaharian di bidang pertanian dengan sistem ladang berpindah. Pola kolektivisme terasa lebih kental pada budaya orang Flores sebab dapat mempersatukan masyarakatnya agar mereka (para anggota dari sub budaya tertentu) mampu bertahan hidup dan mampu pula mengatasi tantangan, ancaman maupun gangguan terutama yang berasal dari alam.

Banyak sekali bahasa daerah yang berbeda yang digunakan oleh masyarakat di Flores kendati jarak wilayahnya tidak terlalu jauh. Dalam satu wilayah kecamatan terdapat bahasa yang berbeda yang dipakai oleh masyarakatnya. Hal ini bisa memicu konflik antarbudaya karena satu kata yang sama bisa berbeda sekali maknanya. Dan konflik antarbudaya bisa dipicu dari kesalahan manafsirkan makna dari kata yang diungkapkan itu. Karena itu, bahasa Indonesia di Flores menjadi sangat penting dan hampir semua wilayah bahkan yang paling terpencil sekalipun, masyarakatnya berusaha untuk belajar bahasa Indonesia (masyarakat sering menyebut bahasa Indonesia sebagai "bahasa Melaju"). Sekolah-sekolah yang dikembangkan oleh misi Gereja sangat membantu dalam mensosialisasikan bahasa Indonesia.

Sebuah contoh tentang pemakaian satu "kata" yang sama dalam pengucapan (verbal) dan secara literasi (tulisan) tetapi memiliki arti yang berbeda secara ekstrim adalah kata: "mena". Mena untuk masyarakat di Nagekeo artinya "di sana" tetapi untuk masyarakat di Lamaholot artinya kasar sekali yaitu kata makian untuk kaum perempuan. Dan bagi masyarakat Lamaholot, jika perempuan "dimaki" maka bisa memicu perang.

Biasanya yang dilakukan untuk meligitimasi kekuasaan adalah dengan ritus tertentu bagi kelompok yang berhasil mengalahkan kelompok lain dalam "perang tanding" merebut wilayah (tanah).

Akan tetapi hingga sekarang, konsep "perang tanding” telah bergeser bukan untuk melegitimasi kekuasaan tetapi lebih karena sentimen suku atau selisih paham pada anggota antarsuku yang mendiami wilayah tertentu. Biasanya suku-suku itu bertetangga dan wilayahnya dipisahkan dengan sungai atau gunung, batu atau pohon besar tertentu. Kembali faktor alam pun turut memainkan peranannya dalam sistem komunikasi antarsuku dalam budaya orang Flores.

Selain kata, terdapat juga simbol yang digunakan oleh masyarakat di Pulau Flores yang menunjukkan bahwa mereka merupakan satu kelompok dari suku atau clan tertentu tetapi bisa 
memicu konflik antarbudaya. Misalnya di Flores bagian Barat, terdapat simbol kayu yang mempersatukan yang disebut dengan nama "peo" (Suku Nagekeo) dan "ngadu" (Suku Ngada yang merupakan altar persembahan untuk seremoni tradisional). Biasanya masyarakat dari kedua suku ini member nama pada keturunannya sesuai dengan nama tumbuhan atau hewan yang diyakini sebagai "inkarnasi" nenek-moyang mereka.

Sehingga nama-nama seperti: meo (kucing), lako (anjing), kaju (kayu), watu (batu) adalah nama-nama kebanggaan mereka. Tetapi justru di wilayah tetangga seperti di Ende dan Sikka nama-nama tersebut tidak boleh diucapkan atau dikenakan pada diri orang atau anak manusia (dianggap Pemali). Masing-masing suku di Pulau Flores memiliki nama untuk kelompok suku mereka, seperti: da Silva (dari hutan), da Cunha, da Gomez, Parera, Conterius, Hayon, Koten (kepala), Tukan (perut), Kleden, Kaju (kayu), Watu (batu), Meo (kucing), Lako (anjing).

\section{b. Konflik Asimilasi Budaya}

Budaya orang Flores memiliki tingkat toleransi untuk kelompoknya dalam hal adanya orang dari luar kelompoknya yang ingin "masuk" ke dalam kelompoknya. Namun toleransi tersebut harus dibarengi dengan prasayarat yang harus dipenuhi oleh "orang baru" tersebut. Hal ini biasanya terjadi melalui perkawinan beda suku.

Namun sering dapat memicu konflik apabila tidak terpenuhi aturan adat seperti belis (mahar) yang jumlah dan bentuknya bisa sangat sulit untuk dipenuhi. Misalnya seorang laki-laki dari Maumere (Sikka) ingin meminang/melamar gadis dari Manggarai (Ruteng) maka laki-laki dan keluarganya harus memenuhi persayaratan belis (mahar) berupa: kerbau dengan jumlah 50 ekor (1 ekor kerbau sekarang harganya 10 juta), emas 50 gram, uang 150 juta. Jika perempuannya dari Sikka, maka lakilaki dari Ruteng itu harus membayar belis (mahar) berupa: kuda 50 ekor, emas 50 gram, gading 5 batang, uang 50 juta. Beratnya beban belis sehingga banyak sekali perempuan di wilayah Flores yang menjadi "perawan tua" atau menempuh jalan pintas, yang disebut dengan istilah "kawin lari" (si laki-laki nekat membawa kabur gadis yang ditaksirnya, setelah punya anak barulah diurus ritus rekonsiliasi yang ketentuannya bisa lebih barat atau ringan sesuai dengan hasil negosiasi antara kedua suku atau kedua keluarga).

Gender issue menjadi isu yang menarik ketika kita "membaca" budaya orang Flores. Secara dominan konsep masculinity menyebar hampir di semua wilayah budaya di Flores. Namun pada beberapa tempat tertentu, seperti di Flores bagian Barat (khususnya di Nagekeo dan beberapa suku tertentu di Flores bagian Tengah) menganut konsep femininity.

Setiap suku pada budaya orang Flores memiliki sistem makna yang khas untuk konsep masculinity dan femininity. Misalnya simbol "tanduk kerbau" untuk menyatakan kekuasaan kaum laki-laki pada suku tertentu di Flores. Semakin banyak tanduk kerbau yang terdapat pada rumah adat, semakin tinggi kekuasan kelompok suku tersebut. Selain itu simbol "corak atau motif tenunan" menunjukkan bahwa seorang perempuan pantas dihargai dalam budaya yang sistem kekerabatannya bersifat patrilineal. 


\section{c. Konflik dengan Peradaban Modern}

Konflik masyarakat Pulau Flores dengan peradaban modern menjadi suatu fenomena baru yang muncul ketika media televisi telah masuk hingga ke pelosok desa di Pulau Flores. Apalagi dengan temuan terbaru teknologi komunikasi, seperti handphone, blackberry, internet, dll, menghadapkan masyarakat di Pulau Flores pada dua tegangan yakni di satu pihak teknologi komunikasi itu semakin memudahkan komunikasi antar masyarakat di wilayah dengan kondisi geografis dan topografis yang berbukit-bukit itu. Tetapi di pihak lain teknologi komunikasi itu pun menghilangkan sebagian identitas yang khas dimiliki oleh orang-orang Flores.

Memang hal ini belum merambah seluruh masyarakat Flores pada umumnya, tetapi fenomena ini menjadi sesuatu yang menarik untuk diamati. Yang dimaksudkan dengan hilangnya sebagian identitas khas orang Flores adalah sebagian kaum perempuan di Flores menjadi "tidak percaya diri" dengan kondisi fisik mereka, seperti : berambut ikal (keriting), berkulit sawo matang/coklat, dan berbusana sarung tenun.

Mereka lebih terobsesi dengan reklame kecantikan di mana tubuhtubuh ideal biasanya ditampilkan dalam majalah, film, televisi, dan dunia periklanan, yang menggambarkan atau menyajikan sosok perempuan ideal sebagai suatu figur perempuan yang langsing, berambut lurus terurai, berkaki indah, paha, pinggang dan pinggul ramping, payudara cukup besar, dan kulit putih mulus.

Nah... memang berdampak menguntungkan bagi yang membuka bisnis salon kecantikan. Laris manis...!, khususnya dalam upaya meluruskan rambut-rambut ikal (keriting) perempuan-perempuan hampir di semua wilayah di Pulau Flores. Kain tenun yang selalu diburu oleh banyak wisatawan domestik dan mancanegara, rupanya tidak lagi dikenakan oleh sebagian besar masyarakatnya sehingga mendorong pemerintah daerah mencanangkan hari berbusana tenun daerah bagi para pegawai negeri. Gadis-gadis desa pun enggan ke ladang dan bergabung dengan kelompokkelompok tani, karena takut kalau kulit mereka menjadi hitam. Mereka mengganti molang (ramuan tradisional yang biasa dipakai untuk menjaga kulit khususnya kaum perempuan) dengan berbagai cream pemutih kulit yang ditawarkan oleh iklan di media (televisi, majalah atau media on line).

Konflik dengan peradaban modern ini pun berdampak pada menurunnya rasa bangga pada budaya sendiri. Sehingga upaya untuk melestarikan budaya dengan cara belajar juga mengalami kemerosotan. Masih beruntung di bidang pendidikan, pemerintah mencanangkan program pendidikan muatan lokal. Jika dulu persyaratan seorang wanita diinisiasi menjadi seorang wanita dewasa dan boleh dilamar oleh seorang pria adalah harus tahu menenun sarung, kini bukan menjadi kewajiban lagi bagi perempuan-perempuan di semua desa atau kampung di wilayah Pulau Flores.

Terjadi suatu lompatan budaya yang sangat jauh sehingga kebudayaan warisan leluhur terancam punah. Yang sekarang menjaga tradisi budaya adalah generasi tua. Kita berharap kurikulum muatan lokal bisa membantu menjaga warisan budaya tersebut.

Kesalahan-kesalahan komunikasi yang terjadi akibat adanya perbedaan latarbelakang budaya dari 2 (dua) orang atau lebih dapat diminimalisir atau dinetralisir melalui pendidikan 
dan pengalaman ada bersama dengan orang-orang dari budaya yang berbeda. Hal ini akan mengasa keterampilan dan keterbukaan diri untuk dapat berinteraksi dengan orang-orang dari budaya lain. Selain itu, ciri-ciri budaya sendiri memungkinkan orang-orang dari budaya yang berbeda dapat saling berinteraksi, saling belajar dan bertukar pesan secara baik dan benar. Ciri-ciri budaya itu meliputi: dapat dipelajari atau bukan bawaan; dapat disampaikan dari orang ke orang, dari kelompok ke kelompok dan dari generasi ke generasi; bersifat dinamis atau terus berubah; selektif; berbagai unsur budaya saling berkaitan; etnosentrik (Larry A. Samovar dan Richard E. Porter dalam Mulyana, 2012).

Pandangan antropologi budaya menyebutkan bahwa kebudayaan merupakan kerangka yang membentuk (mengorganisir) kehidupan. Kebudayaan bisa dipandang sebagai kesepakatan-kesepakatan anggota masyarakat untuk mengatur tingkah lakunya. Pengaruh kebudayaan dapat disadari, dapat pula tidak disadari. Selain itu ada keanekaragaman budaya. Dapat pula terjadi konfrontasi antara suatu kebudayaan dengan kebudayaan lainnya dan dominasi suatu kebudayaan terhadap kebudayan lainnya.

Kesalahan-kesalahan komunikasi yang terjadi melalui permainan bahasa tentu saja dilatarbelakangi oleh banyak faktor, di antaranya adalah faktor perbedaan unsur-unsur budaya. Permainan bahasa dapat terjadi baik secara verbal maupun secara nonverbal. Kesalahan komunikasi melalui permainan bahasa dapat dihindari jika orang-orang dari budaya yang berbeda yang berada dalam satu organisasi, lembaga atau komunitas sudah mengetahui dan memahami simbolsimbol verbal dan non-verbal yang dipakai dalam berinteraksi. Kesalahan komunikasi yang disadari tentu saja akan membawa setiap orang dari budaya yang berbeda kepada pemahaman akan arti dan makna pada simbol-simbol yang digunakan secara verbal dan non-verbal dalam lintasan komunikasi.

Teori komunikasi lintas budaya sesungguhnya dapat mendorong perkembangan komunikasi dan media komunikasi serta perkembangan dari budaya itu sendiri. Hal ini karena salah satu sifat dari budaya itu adalah dinamis. Komunikasi sebagai wujud dari budaya menunjukkan kreasi (hasil ciptaan) dan pengiriman pesan yang sifatnya serupa (homogeneous) kepada sejumlah besar audiens yang beraneka ragam (heterogeneous) melalui atau dengan menggunakan media menunjukkan adanya relasi "yang abadi" atau yang terus-menerus ada antara budaya dan komunikasi.

Komunikasi lintas budaya dianggap penting baik secara teoretis maupun secara praksis. Hal ini karena kebudayaan atau budaya bukan hanya tata nilai atau suatu suprastruktur yang merupakan cerminan dari infrastruktur. Kebudayaan merupakan totalitas dari obyek (kebudayaan "intelektual"), yang didukung oleh subyek (individu, kelompok, kelas, sektor-sektor masyarakat).

Keanekaragaman budaya dapat menimbulkan konfrontasi antara suatu kebudayaan dengan kebudayaan lainnya dan dapat pula memunculkan dominasi suatu kebudayaan terhadap kebudayaan lainnya. Namun keanekeragaman budaya itu dapat memunculkan harmonisasi bila ada keterbukaan dan keterampilan dalam berkomunikasi lintas budaya. Selain 
itu, kemampuan berkomunikasi lintas budaya akan membuat hidup manusia lebih sukses.

Konflik budaya pada masyarakat di Pulau Flores juga ternyata ditimbulkan oleh kesalahan dalam menggunakan media komunikasi. Penggunaan telepon genggam (handphone) di dalam masyarakat di Pulau Flores dapat menciptakan salah persepsi atau memicu konflik baik verbal maupun nonverbal ketika melalui alat komunikasi tersebut dapat disebarkan isu-isu provokatif atau pun ejekanejekan yang sensitif terhadap kehormatan suku atau agama tertentu yang dianut di dalam masyarakat di Pulau Flores. Teknologi komunikasi yang digunakan dapat menipu atau memanipulasi.

Penipuan atau manipulasi teknologi komunikasi dipengaruhi oleh sistem dan aktor (manusia) yang memiliki kepentingan baik politis, eknomis maupun kepentingan sosial (kelompok, agama, etnis). Manipulasi seperti ini oleh Jean Baudrillard disebutnya sebagai hiper-realitas (O’Donnel, 2009 : 45).

\section{Kesimpulan}

Menarik sekaligus menantang ketika upaya untuk "membaca" budaya orang Flores ini terjadi dalam arus perubahan zaman atau peradaban. Menjadi menarik karena unsur-unsur budaya orang Flores masih ada hingga saat ini teristimewa pada simbol-simbol yang tentu saja mewakili sistem makna dari setiap wilayah budaya yang ada di Pulau Flores. Menantang karena unsurunsur budaya orang Flores lambat laun tergerus oleh arus perubahan zaman atau peradaban itu sendiri.

Marsel Robot (dalam Kleden, 2007: 315-316) mencatat bahwa pada masyarakat di wilayah Flores bagian
Barat, kaum perempuan di desa sudah tidak lagi menggunakan alat timba tradisional dan terbuat dari bambu yang dikenal dengan nama loran, jenggok, laduk. Beberapa rumah telah dipasang jam dinding. Itu berarti pula bahwa mereka telah memberi makna pada waktu, dan bekerja berdasarkan waktu, dapat menentukan kapan ke kebun, kapan pulang, kapan memberikan makanan ternak. Jam dinding telah menebang bayang pohon dadap di pinggir rumah sebagai perhitungan waktu hendak ke kebun, jam dinding telah melenyapkan suara kaka totok (sejenis burung padang) yang dengan setia mengisyaratkan akan hari sudah senja, jam dinding telah menghalau awan ke lima yang mengisyaratkan para petani harus ke rumah karena hari mulai dijemput gelap. Perubahan telah terjadi di sana, keganjilan pun telah terjadi di sana.

Peluang-peluang yang dapat dikembangkan untuk membangun dialog lintas budaya di wilayah Pulau Flores adalah sistem nilai budaya Flores, seperti cara berpikir sosial-kolektif, kosmosmistis, religi-magis, simbolis, moralreligius menjadi kekuatan pemersatu dalam mambangun daerah (termasuk dalam membangun NKRI). Beberapa nilai praktis sebagai penunjang pembangunan, antara lain semangat kekeluargaan, kerohanian, ketulusan, dan sopan santun, telah terbentuk dalam interaksi sosial antaretnik dan lestari sampai saat ini.

Secara geografis, Pulau Flores menunjukkan warna tertentu bagi kehidupan masyarakatnya baik secara ekonomis, politis yang bersifat strategis di kawasan Indonesia bagian timur dan pintu gerbang ke kawasan Pasifik Selatan dan Australia. Kondisi geostrategis itu didukung oleh kekayaan alam, misalnya sumber daya mineral dan energi yang belum dikelola, flora dan fauna, serta aneka ragam budaya etnik. Faktor-faktor itu merupakan kekayaan terpendam 
sekaligus merupakan kekuatan yang dapat ditumbuhkembangkan sebagai aset ekonomi bagi kehidupan sosial masyarakat Pulau Flores.

Selain faktor geografis tersebut di atas, hasil-hasil pembangunan yang bersifat material dan imaterial telah menerobos isolasi geografis, sosial dan psikologis serta antaretnik di wilayah Pulau Flores. Hal ini merupakan bukti keberhasilan implementasi konsep dan nilai-nilai budaya melalui dialog yang hidup (komunikasi antarbudaya). Dampak positif dari urgensitas dialog lintas budaya pada masyarakat Pulau Flores dapat merangsang derap kemajuan peradaban di berbagai bidang kehidupan masyarakatnya. Dapat kita bayangkan jika wilayah dengan topografi yang berbukitbukit ini tidak terjadi dialog yang hidup antaretnik. Tentu saja dampak negatifnya akan lebih menonjol, seperti perang antarsuku, primordialisme yang tinggi, hubungan antaretnik menjadi tidak harmonis, saling curiga satu sama lain.

Hal lain yang perlu disadari oleh masyarakat pendukung budaya di Pulau Flores adalah sikap keterbukaan untuk belajar dari keberhasilan etnik-etnik lain, baik yang ada bersama di wilayah Pulau Flores maupun yang ada di luar Pulau Flores. Hal ini dipandang sebagai suatu terobosan yang kreatif dan dinamis.

\section{Daftar Pustaka}

Adur, Gabriel. 2009. "Membaca Pencerahan Masyarakat Flores dan NTT". Artikel dalam kolom opini pada Harian Umum Flores Pos.

Fiske, John. 2007. Cultural and Communication Studies, Yogyakarta: Jalasutra.

Gudykunst, William B. dan Bella Mody, (ed.). 2001. Handbook of International and Intercultural Communication, Second Edition. London: Sage Publication.

Kleden, Tony, Maria Matildis Banda dan Dion DB Putra. (eds). 2007. Pos Kupang, Suara Nusa Tenggara Timur. Kupang: PT. Timor Media Grafika.
Littlejohn, Stephen W. dan Karen A. Foss. (eds). 2009. Encyclopedia of Communication Theory.

California: Sage Publications.

Martin, Judith N. dan Thomas K. Nakayama. 2004. Intercultural Communication in Contexts. New York: McGraw Hill.

Mulyana, Deddy. 2012. Komunikasi Transbudaya. Materi Kuliah Program Doktor Fikom Universitas Padjajaran, Bandung.

O’Donnell, Kevin. 2009. Postmodernisme. Yogyakarta: Kanisius.

Tubbs, Stewart L. dan Sylvia Moss. 1996. Human Communication. Bandung: Remaja Rosdakarya. 